\title{
Changing patterns of corneal disease and associated vision loss at a rural African hospital following a training programme for traditional healers
}

\author{
Paul Courtright, Susan Lewallen, Steve Kanjaloti
}

BC Centre for Epidemiologic and International Ophthalmology, University of British Columbia, Vancouver, Canada

P Courtright

$S$ Lewallen

Orbis International, New York, USA

P Courtright

International Eye Foundation, Bethesda, MD, USA

$S$ Lewallen

Chikwawa District Hospital, Chikwawa, Malawi

S Kanjaloti

Correspondence to: P Courtright, BC Centre for Epidemiologic and International

Ophthalmology, Department of Ophthalmology,

University of British

Columbia, St Paul's

Hospital, 1081 Burrard

Street, Vancouver, BC

V6Z 1Y6 Canada.

Accepted for publication 4 April 1996

\begin{abstract}
Aims/background-Use of African traditional eye medicines (TEM) is associated with the presence of corneal disease, delay in presentation, and vision loss. An interactive training programme was conducted with traditional healers in Chikwawa District, Malawi and changes in the pattern of corneal disease assessed in patients presenting to the district hospital after the training.
\end{abstract}

Methods-All patients presenting to the district hospital with corneal disease for a 15 month period before intervention and a 12 month period after intervention were enrolled in the study. Interviews and examinations were carried out by the same person using a standardised, pretested form.

Results-Among the 175 pre-intervention and 97 post-intervention patients, delay in presentation improved only slightly. Blindness among patients reporting the use of TEM decreased from $44 \%$ to $21 \%$; bilateral corneal disease in patients using TEM decreased from $31 \%$ to $10 \%$. Multivariate analysis demonstrates that poor vision in corneal disease patients continues to be associated with TEM use and distance from the district hospital.

Conclusion-As there were no other relevant eye health programmes in the district it is believed that this collaborative eye care programme with the traditional healers was likely to have been responsible for many of the changes in the pattern of corneal disease in the district. Although the changing patterns are encouraging and are likely to improve with additional collaboration, distance to a district hospital will continue to be a barrier to timely use of Western eye care services. (Br F Ophthalmol 1996;80:694-697)

Traditional eye medicines (TEM) have been associated with corneal disease in a number of settings in sub-Saharan Africa. ${ }^{1-7}$ In our previous work on the subject in Malawi we found that TEM use was reported by $34 \%$ of patients presenting to two district hospital with corneal disease. ${ }^{6}$ Patients who used TEM took almost four times as long to reach the district hospitals as those who did not. Blindness was three times more frequent in patients using TEM compared with patients not using TEM. These findings, and the recognition that African traditional healers are widely accepted by rural Africans, indicated a need to try to encourage appropriate eye care practices among community based traditional healers.

Findings from our original corneal disease investigations and from a series of interviews with a sample of traditional healers in the district were used to develop an interactive educational programme with the healers. Details of this programme are given elsewhere. ${ }^{8}$ Briefly, the local ophthalmic medical assistant (SK) held a series of four 1 day training sessions with about 240 healers (approximately $20 \%$ of healers in the district) at eight different sites throughout Chikwawa District (Fig 1) One element of the training involved recognition and treatment of red eye. We did not discourage patients from seeking care from healers; nor did we discourage traditional healers from using traditional methods unless they involved direct application of substances to the eye. Healers were encouraged to refer their patients to the ophthalmic medical assistant at the district hospital if TEM failed to result in improvement within 3 days. As one component of an evaluation of our eye care programme with the healers we sought to assess changes in the presentation of corneal disease at the district hospital after the initiation of the programme. Changes we were most interested in measuring were decrease in the delay from onset of symptoms to presentation to district hospital for care and decrease in the severity of the corneal disease (as defined by visual acuity on presentation).

\section{Material and methods}

STUDY METHODS

To measure changes in the delay in presentation and visual acuity, all patients presenting to Chikwawa District Hospital with corneal disease before and after programme implementation underwent a standardised interview and examination. Corneal disease was defined as a corneal lesion in which fluorescein stain was visible by torch examination. Details of our methods have been published ${ }^{6}$ with findings from the pre-programme period. The interview covered demographic characteristics, treatment received before presentation at the district hospital, and date of onset of symptoms. Proximity to the district hospital was 
Table 1 Demographic and clinical information of patients presenting to Chikwawa District Hospital with corneal disease

\begin{tabular}{|c|c|c|c|c|}
\hline \multirow{3}{*}{ Residence: } & \multicolumn{2}{|c|}{$\begin{array}{l}\text { Post-intervention period } \\
\text { No }(\%)\end{array}$} & \multicolumn{2}{|c|}{$\begin{array}{l}\text { Pre-intervention period } \\
\text { No }(\%)\end{array}$} \\
\hline & & & & \\
\hline & & & & \\
\hline Nearby subdistrict & 50 & $(16.17)^{\star}$ & 80 & $(16.78)^{\star}$ \\
\hline Distant subdistrict & 44 & $(1.72)$ & 95 & $(2.41)$ \\
\hline \multicolumn{5}{|c|}{ Number of days between first symptom and presentation at the hospital: } \\
\hline$<7$ days & 28 & $(29.8)$ & 57 & $(32.8)$ \\
\hline $7-20$ days & 38 & $(40.4)$ & 58 & $(33.3)$ \\
\hline $21+$ days & & $(29.8)$ & 59 & (33.9) \\
\hline Mean days (SD) & 18.8 & $(22.5)$ & 20.2 & $(24.1)$ \\
\hline \multicolumn{5}{|c|}{ Laterality of corneal disease: } \\
\hline Unilateral & 86 & (91.5) & 141 & $(80.6)$ \\
\hline Bilateral & 8 & $(8.5)$ & 34 & $(19.4)+$ \\
\hline \multicolumn{5}{|c|}{ Western medicines used before presentation: } \\
\hline Reported & 21 & $(21.6)$ & 91 & $(52.3)$ \\
\hline Not reported & 76 & $(78.4)$ & 83 & $(47.7) \dagger$ \\
\hline \multicolumn{5}{|c|}{ Vision in the affected eye: } \\
\hline$>6 / 18$ & 54 & $(73.0)$ & 85 & $(52.1)$ \\
\hline $6 / 18-3 / 60$ & 15 & $(16.0)$ & 38 & $(23.3)$ \\
\hline$<3 / 60$ & 15 & $(16.0)$ & 40 & $(24.5)$ \\
\hline \multicolumn{5}{|l|}{ Best corrected vision: } \\
\hline$>6 / 18$ & 83 & $(96.5)$ & 141 & (86.5) \\
\hline $6 / 18-3 / 60$ & 2 & (2.3) & 13 & $(8.0)$ \\
\hline$<3 / 60$ & 1 & $(1.2)$ & 9 & $(5.5)$ \\
\hline \multicolumn{5}{|c|}{ Traditional eye medicines used: } \\
\hline Reported & 30 & $(30.9)$ & 71 & $(40.6)$ \\
\hline Not reported & 67 & $(69.1)$ & 104 & $(59.4)$ \\
\hline
\end{tabular}

* Nearby subdistricts are Kasisi and Katunga. Distant subdistricts are the remainder. Values in parenthesis reflect number of corneal disease patients per 1000 population calculated on an annual basis.

† Differences (post-intervention compared with pre-invention) are significant $(p<0.05)$.

defined according to residence; residents of the subdistricts of Katunga and Kasisi were defined as nearby residents while those living in other subdistricts were defined as distant residents. TEM use is defined as use of any traditional eye medicine (face wash, fume bath, or traditional eyedrop) administered by a traditional healer. All examinations and interviews were conducted by one person (SK). Data were recorded from January 1992 to March 1993 (pre-intervention) and from January to December 1994 (post-intervention). The training programme (three sessions) was

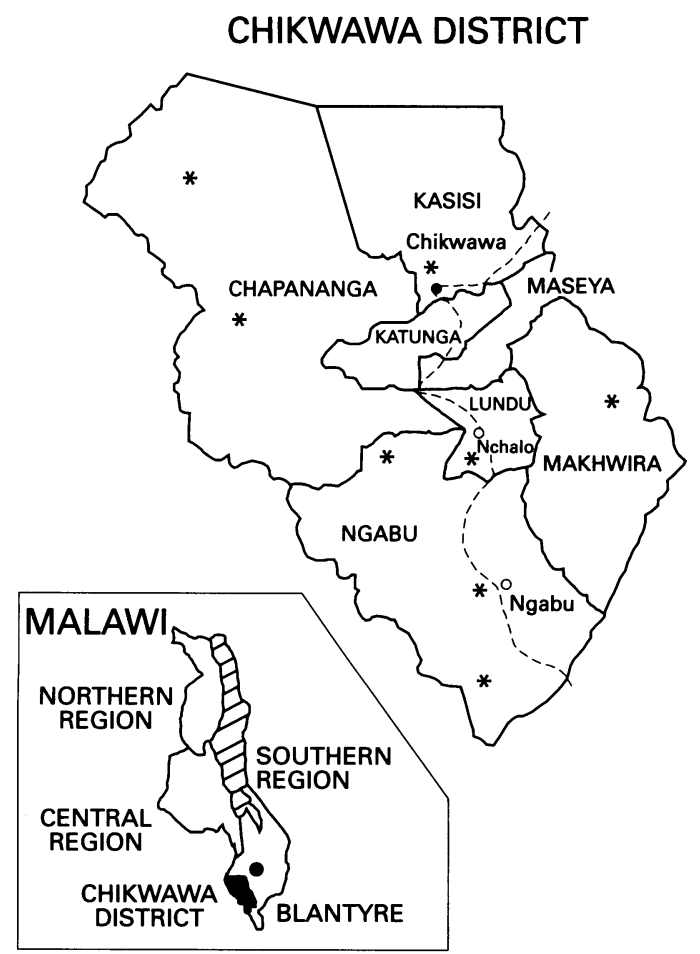

Figure 1 Map of Chikwawa District and neighbouring districts. conducted from July to December 1993. An additional session was held in March 1994 at the request of the healers and the funding agencies. The cost of all four sessions was approximately US\$3 per healer.

STUDY SITE

Chikwawa District (1994 estimated population, 400000 ) served as our project site. The residents are rural subsistence farmers; about $5-10 \%$ of the population live in the three main trading centres. There is a mission hospital in Nchalo (no eye care facilities) and a government district hospital in Chikwawa. The district ophthalmic medical assistant is located at the district hospital. Western eye medicines are available only at the district hospital or at health centres. There are approximately 1200 traditional healers in the district. The only other community based eye care activity under way in the district involved a small trial to determine if village health volunteers and aphakic patients could be cataract surgery motivators; no activity (except ours) targeted general eye complaints or the use of TEM.

\section{ANALYTIC APPROACHES}

We compared delay in presentation and vision in the affected eye according to TEM use in the two time periods. As TEM is only one contributor to corneal disease in the district we also sought to assess demographic and clinical factors associated with poor vision in corneal disease patients. For univariate analyses we used standard $\chi^{2}$ tests and Student's $t$ tests to compare findings from the two periods. To assess the independent contribution of factors to the presence of poor vision (visual acuity defined as $<6 / 18$ ) we constructed a stepwise logistic regression model that included characteristics associated with poor vision in our univariate analysis.

\section{Results}

During the pre-intervention period 175 patients were enrolled in the study. During the post-intervention period 169 patients were enrolled in the study. Forms for 72 patients seen during the final 5 months of the post-intervention period were lost; our results for the post-intervention period reflect findings from 97 patients.

A comparison of the pre- and postintervention records reveals no change in the age, sex, or residence distribution of patients presenting to the district hospital (Table 1); the two adjoining subdistricts (nearest to the district hospital) continued to account for half of all corneal disease patients. Our evaluation of reported TEM use revealed a slight (non-significant) drop from $41 \%$ to $31 \%$. There was no change in the age, sex, or residence distribution of patients reporting TEM use in the two periods; patients living further from the hospital continued to report use of TEM more commonly than those living near the hospital.

The overall decrease in delay in presentation was insignificant, from a mean number of days of 20.2 to 18.8 . Among patients reporting the 
Table 2 Change in use of traditional eye medicines (TEM) in patients with corneal disease presenting to Chikwawa District Hospital

\begin{tabular}{|c|c|c|c|}
\hline & \multicolumn{2}{|c|}{ No reporting TEM use (\%) } & \multirow{2}{*}{$\begin{array}{l}\text { Odds ratio (95\% } \\
\text { confidence interval) }\end{array}$} \\
\hline & Post-intervention & Pre-intervention & \\
\hline \multicolumn{4}{|l|}{ Residence: } \\
\hline Nearby residents & $12(40.0)^{\star}$ & $22(31.0)^{\star}$ & \\
\hline Distant residents & $18(60.0)$ & $49(69.0)$ & $1.5(0.6,3.9)$ \\
\hline \multicolumn{4}{|c|}{ Number of days since first symptom: } \\
\hline$<7$ & $3(10.0)$ & $7(9.9)$ & $1.0 \dagger$ \\
\hline $7-20$ & $10(33.3)$ & $18(25.4)$ & $1.3(0.2,8.2)$ \\
\hline $21+$ & $17(56.7)$ & $49(64.8)$ & $0.8(0.2,4.5)$ \\
\hline \multicolumn{4}{|c|}{ Laterality of corneal disease: } \\
\hline Bilateral & $3(10.0)$ & $22(31.0)$ & \\
\hline Unilateral & $27(90.0)$ & $49(69.0)$ & $0.3(0.1,1.0) \ddagger$ \\
\hline \multicolumn{4}{|c|}{ Western medicines used before presentation: } \\
\hline Reported & $15(50.0)$ & $54(77.1)$ & \\
\hline Not reported & $15(50.0)$ & $16(22.9)$ & $0.3 \quad(0.1,0.8) \ddagger$ \\
\hline \multicolumn{4}{|c|}{ Visual acuity in the affected eye: } \\
\hline$\geqslant 6 / 18$ & $11(39.3)$ & $18(25.5)$ & $1.0 \ddagger$ \\
\hline $6 / 18-3 / 60$ & $11(39.3)$ & $21(30.0)$ & $0.9(0.3,2.8)$ \\
\hline$<3 / 60$ & $6(21.4)$ & $31(44.3)$ & $0.3(0.1,1.1)$ \\
\hline
\end{tabular}

* Nearby residents are from Kasisi and Katunga. Distant residents are from the remaining subdistricts.

† Reference group.

$\ddagger$ Statistical significance at $\mathrm{p}<0.05$.

Table 3 Visual acuity (affected eye) in patients with corneal disease presenting to Chikwawa District Hospital during the post-intervention period

\begin{tabular}{|c|c|c|c|}
\hline & \multicolumn{2}{|c|}{ Post-intervention visual acuity } & \multirow[b]{2}{*}{$\begin{array}{l}\text { Odds ratio } \\
\text { (95\% CI) }\end{array}$} \\
\hline & $\begin{array}{l}\geqslant 6 / 18 \\
\text { No }(\%)\end{array}$ & $\begin{array}{l}<6 / 18 \\
\text { No }(\%)\end{array}$ & \\
\hline \multicolumn{4}{|l|}{ Residence: } \\
\hline Nearby resident & $33(60.0)$ & $11 \quad(34.4)$ & \\
\hline Distant resident & $22 \quad(40.0)$ & $21 \quad(65.6)$ & $2.9(1.1,7.9)^{\star}$ \\
\hline \multicolumn{4}{|l|}{ Age: } \\
\hline$<50$ years & $47 \quad(85.4)$ & $21 \quad(65.6)$ & \\
\hline $50+$ years & $8(14.6)$ & 11 (34.4) & $3.1(1.0,9.9)$ \\
\hline \multicolumn{4}{|c|}{ Number of days since first symptom: } \\
\hline$<7$ & $23 \quad(41.8)$ & $3(9.4)$ & $1.0 \dagger$ \\
\hline $7-20$ & $21 \quad(38.2)$ & $14 \quad(43.8)$ & $0.2(0.0,0.9)^{\star}$ \\
\hline $21+$ & $11 \quad(20.0)$ & $15 \quad(46.9)$ & $0.1(0.0,0.4)^{\star \star \star}$ \\
\hline Mean days (SD) & $28.1(29.7)$ & $13.6(16.3)^{\star}$ & \\
\hline \multicolumn{4}{|c|}{ Western medicines used before presentation: } \\
\hline Reported & $8 \quad(14.5)$ & 11 (34.4) & \\
\hline Not reported & $47 \quad(85.5)$ & $21 \quad(65.6)$ & $0.3(0.1,1.0)$ \\
\hline \multicolumn{4}{|c|}{ Traditional eye medicine used reported: } \\
\hline Not reported & $43 \quad(79.6)$ & $13 \quad(43.3)$ & \\
\hline Reported & 11 (20.4) & $17 \quad(56.7)$ & $5.1(1.7,15.4)^{\star \star \star}$ \\
\hline
\end{tabular}

Statistical significance at ${ }^{\star} p<0.05,{ }^{\star \star \star} p<0.001$.

† Reference group. sis were age, subdistrict of residence (proxy for distance to hospital), delay in presentation, and use of TEM (Table 3 shows post-intervention only). Logistic regression analysis revealed that reported use of TEM was associated with poor vision in both the pre-intervention period (odds ratio (OR) 4.1, 95\% confidence interval (CI) $1.8,9.2)$ and the post-intervention period (OR 4.7, 95\% CI 1.6, 13.7). Furthermore, regardless of TEM use, patients living distant from the hospital had a 3.5 -fold risk $(95 \% \mathrm{CI}$ $1.2,9.9)$ of having poor vision.

\section{Discussion}

The potential for having African traditional healers involved in prevention of blindness activities has not been evaluated. The interest by healers in Chikwawa District in our training programme suggested to us that healers could have a positive role in blindness prevention. We recorded an $80 \%$ increase in patient selfpresentation for cataract surgery after the initiation of training. ${ }^{9}$ Much criticism of African healers is focused on their application of caustic substances to the eye. We sought to change this behaviour while encouraging them to continue other non-harmful eye practices and refer patients to the ophthalmic medical assistant. It was not feasible to observe the actual practices of healers; we chose, instead, to measure the final outcome: severity of corneal disease and vision loss among patients presenting to the district hospital. It is probably the most useful criterion for national prevention of blindness programmes to measure success of training, as it indicates what changes are possible by a relatively simple and inexpensive approach.

There are limitations to interpretation of our findings. The change in the pattern of corneal disease and associated vision loss in Chikwawa District reflect social and economic factors in the district as well as the programme with the healers. We detected a decrease in the use of Western eye medicines (before presentation at the district hospital); this is probably due to the fact that these products were less available in the health centres and their unavailability may explain a decrease in use of health centres for primary eye care. A consequence of this is the increased use of traditional healers as first treatment sources and direct presentation at the district hospital.

Our healer training programme only reached about 240 healers of the estimated 1200 healers in the district. Many patients enrolled in the post-intervention period were treated by healers who were not involved in the programme; we did not have the capacity to determine which patients were treated by which healer. In some cases, however patients brought 'referral letters' from a healer. Not all of the participating healers agreed with all tenets of the programme; in particular, a few healers continue to maintain that traditional eyedrops are beneficial and do not refer their patients to the district hospital when recommended.

We did not find a significant reduction in the delay in presentation; the loss of forms (in the 
post) from the last 5 months of the postintervention period was unfortunate, although there was no selection related to the loss. The trend to a decrease in the length of delay (especially in the last 6 months) suggests that multiple courses may be crucial in changing behaviours. Single (one time only) meetings with healers are unlikely to result in much change in practice. Prolonged delay continues to be found among patients living more distant from the district hospital and a 1 to 2 week delay may continue to be common among patients who seek care from healers or health centres before presentation at the district hospital.

Most encouraging was the decrease in the severity of the corneal disease as reflected by the decrease in blindness, visual disability, and bilateral disease. Of particular note is the significant decrease (from $44 \%$ to $21 \%$ ) in blindness among patients who reported using TEM and the significant reduction in the proportion of patients with bilateral corneal disease. This change may have resulted from more direct referral of patients by healers to the district hospital before vision deteriorated substantially or decreased use of traditional eyedrops. Healers were instructed in a simple assessment of vision and many have commented on its usefulness in patient assessment.

The behaviour of eye disease patients who did not come to the district hospital cannot be measured. As there were no community based eye care efforts during pre- and postintervention periods, we suspect that the training is responsible for most of the changes seen. Throughout the programme, healers in subdistrict Ngabu (most distant from Chikwawa and comprising $34 \%$ of the district's total population) reported that many of the patients they referred refused to go to the district hospital because of the distance. Distance continues to be a barrier to the reduction of corneal disease related vision loss. It is unlikely that the transportation infrastructure will improve substantially over the next decade; eye care services must expand beyond the district hospital.
Staffing in the district (and throughout subSaharan Africa) is insufficient, far below recommended levels. ${ }^{10}$

The continued contribution of TEM to poor vision, regardless of age and distance, suggests that further educational efforts with healers are required. There is ample evidence that collaborative efforts with healers must be viewed as a long term programme rather than a short series of training sessions. ${ }^{11} 12$ Although community based education of the general population might appear to be another approach to reducing the impact of TEM, the cost associated with education of the general population is high. Continued collaboration with traditional healers is necessary and programme activities should be integrated into all ophthalmic medical assistant training programmes.

The project was supported by Project ORBIS and the International Eye Foundation, for which the authors are grateful. We would also like to thank the staff of the International Eye Foundation/Malawi for their assistance.

1 Foster A, Gilbert C. Community efforts in the reduction of corneal blindness in developing countries. Refract Corneal Surg 1991;7:445-8.

2 Foster A, Sommer A. Corneal ulceration, measles, and childhood blindness in Tanzania. Br $\mathcal{F}$ Ophthalmol 1987;71: 331-43.

3 Yorston D, Foster A. Traditional eye medicines and corneal ulceration in Tanzania. F Trop Med Hyg 1994;97:211-5.

4 McMoli TE, Bordoh AN, Munube GMR, Bell EJ. Epidemic acute haemorrhagic conjunctivitis in Lagos, Nigeria. $\mathrm{Br} \mathcal{F}$ Ophthalmol 1984;68:401-4.

5 Chirambo MC, Ben-Ezra D. Causes of blindness among students in blind school institutions in a developing country. Br f Ophthalmol 1976;60:665-8.

6 Courtright P, Lewallen S, Kanjaloti S, Divala DJ. Traditional eye medicine use among patients with corneal disease in rural Malawi. Br f Ophthalmol 1994;78:810-2.

7 Lewallen S, Courtright P. Peripheral corneal ulcers associated with use of African traditional eye medicines. $\mathrm{Br}$ f Ophthalmol 1995;79:343-6.

8 Courtright P. Eye care knowledge and practices among Malawian traditional healers and the development of collaborative blindness prevention programmes. Soc Sci Med 1995;41:1569-75.

9 Courtright $P$, Lewallen S, Kanjaloti S. Traditional healers in primary eye care. $\mathrm{Br} f$ Ophthalmol 1995;79:506

10 International Agency for the Prevention of Blindness. Proceedings of the Fifth General Assembly, Berlin, May 9-13, 1994. Haywards Heath: International Agency for the Prevention of Blindness, $\mathrm{p} 31$.

11 Green EC. AIDS and STDs in Africa: bridging the gap between traditional healing and modern medicine. Boulder, CO: Westview Press, 1994

12 Schoepf BG. AIDS, sex and condoms: African traditional healers and the reinvention of tradition in Zaire. Medical Anthropol 1992;14:225-42. 